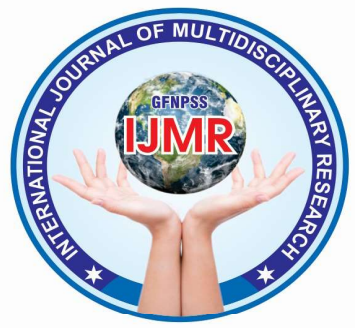

\title{
TO ASSESS KNOWLEDGE OF MOTHERS OF UNDER FIVE CHILDREN ON PREVENTION OF DOMESTIC INJURIES IN SELECTED RURAL AREA OF LALGARH JATTAN SRI GANGANAGAR
}

\author{
MR. SHAKTI SINGH SONI ${ }^{1}$, MR. VIJAY KUMAR ${ }^{2}$, MR. ANKUR SHARMA ${ }^{3}$ \\ ${ }^{1}$ Asso. Prof. cum H.O.D. Mental Health Nursing, S.N. College of Nursing, Sri Ganganagar. \\ ${ }^{2}$ Asst. Prof. Mental Health (Psychiatric) Nursing, S.N. College of Nursing, Sri Ganganagar. \\ ${ }^{3}$ Lecturer Child Health Nursing, S.N. College of Nursing, Sri Ganganagar.
}

Corresponding Email Id: - dr.ssoni0201@gmail.com

\begin{abstract}
Backgrounds: All children are at risk of injury due to their natural curiosity and curiosity to learn new skills and children imitate the behavior of adults from any young children at home especially under the age of five. Those information on home injury prevention information.

Methodology: A Descriptive research design used for the assessment of knowledge of underfive children's mother on prevention of domestic injuries in selected rural area of Lalgarh Jattan Sri Ganganagar. Non-probability convenient sampling technique was used for selection of 100under-five children's mothers. Self-administered Structured Knowledge Questionnaire was used to gather data, which was then evaluated using Descriptive and Inferential Statistics.

Result: The knowledge level of mother of under-five children those participated in this study revealed that out of 100 samples $26 \%$ mothers were having inadequate knowledge $60 \%$ mother knowledge level was moderate and 14\% mother had adequate knowledge there was No Significant association found in level of Knowledge with all Demographic Variables.

Conclusion: Overall mean percentage score of the $58.93 \%$ highest mean percentage $67 \%$ was found on the domain kinds of domestic injuries and list main percentage score $52.8 \%$ was on the domain prevention of domestic injury.
\end{abstract}

Keywords: Knowledge, Mothers, Under-five children, Prevention Domestic injuries.

\begin{tabular}{ccc}
\hline Received & Accepted & Available online \\
\hline $07 / 05 / 2021$ & $27 / 05 / 2021$ & $01 / 06 / 2021$ \\
\hline
\end{tabular}




\section{INTRODUCTION}

Create a healthy future for children. Today's children are the adults of tomorrow. They deserve to inherit a safe, just and healthy world. No work is more important than protecting their environment. ${ }^{1}$

"Healthy environment for children."- WHO theme 2003.

It is said that health is wealth. Health is a multidimensional term that must be understood from a wider context. Safe children are not only tools but also a turning stone to building a stable and prosperous society. Their security, safety, and growth is a necessity for humanity's future progress. ${ }^{2}$

India is the world's second most populated nation, with 13.12 percent of children aged 0 to 5 years old, 15.31 percent of whom live in Rajasthan. ${ }^{3}$

Children are especially susceptible to malnutrition, morbidity, and mortality. The most common causes of death in children under the age of five are falls from balconies, windows, and stairs, lack of supervision, and burns from fires, as well as swelling from every medication. ${ }^{4}$
Accidents are a leading cause of Morbidity and Mortality of infants, and infant deaths as a result of accidents are becoming a more serious public health issue around the world. In today's world, risk exists not only on the roads, but also at home and in playgrounds. For babies and young children who like exploring but are unaware of possible risks, a house is an exciting place to be. ${ }^{5}$

\section{METHODOLOGY}

Research Design: - Descriptive research design.

Settings: -Rural areas at Sri Ganganagar Shivepur head and Lalgarh Jattan.

Population: -The population of present study was Under-Five Children's mothers.

Accessible Population: - Under-Five Children's Mothers in rural area of Sri Ganganagar.

Sample: - 100 Under-Five Children's Mothers in rural area of Lalgarh Jattan, Sri Ganganagar.

Sampling Technique: - Non-probability Convenient Sampling Technique.

Sample Size:-100 Mothers. 


\section{DATA ANALYSIS \&}

\section{INTERPRETATION OF RESULTS}

\section{Section A: - Describing the Frequency} and Percentage Distribution of Selected

Demographic Variable of Under-Five

\section{Children's Mothers}

- Out of 100 mothers maximum number of under-five children's mothers [54\%] were in the age group of 25 years followed by [44\%] were in the age group of 26 to 30 years and [2\%] mother was in age group of about 30 years.

- With regards to education majority of mother [40\%] did their education in primary followed by high school [36 \%] followed by higher secondary [12\%] and graduate [12\%].

- Religion wise the majority of mothers their [88\%] from Hindu religion and remaining [12\%] were from Sikh religion.

- In relation to occupation majority [98\%] mothers were housewife followed by labor [2\%].

- With regard to income of family majority [46\%] family earn less than 1,000 followed by $[26 \%$ ] family earn between
1001 to $5000 \mathrm{Rs} . / \mathrm{month}$ [18\%] family earn between 5001 to 10,000 and remaining [10\%] family earn more than 10000.

- With respect to type of family there were [20\%] mothers belong to nuclear family and there were [78\%]mother's belong to joint family and [2\%] belong to extended family.

- With regard to number of under-five children [52\%] mothers were having one under-five children [42\%] mothers were having to under-five children [6\%] mother were having three under-five children.

- With respect to source of information majority [68\%] mothers were having television is source of information followed by [24\%] as newspaper followed by [4\%] radio and [4\%] health personal as source of information.

Section-B: - Assessing Overall and Domain wise Knowledge among UnderFive Children's Mothers regarding Prevention of Domestic Injuries

It shows the level of knowledge of underfive children's mothers in which majority 


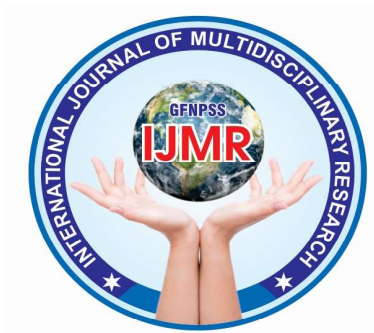

[60\%] mothers had moderate knowledge level [26\%] mothers had inadequate and the remaining $7[14 \%]$ mothers had adequate knowledge level regarding prevention of domestic injuries.

Domain wise knowledge level of under children's mothers regarding prevention of domestic injuries.

Domain-wise awareness standard of mothers of under-five children on domestic injury avoidance, in which domain general information on domestic accidents [44 percent ] had Inadequate Knowledge [26 percent ] had Moderate Knowledge and [30 percent ] had Inadequate Knowledge with respect to kind of domestic injuries [34 percent ] had Adequate Knowledge [38 percent ] had Moderat [4 percent] had little information of how to avoid domestic accidents. had Adequate Knowledge [48 percent ] had Moderate Knowledge [48 percent ] had Inadequate Knowledge with regards to domestic accidents [10 percent ] had Adequate Knowledge [46 percent ] had Moderate Knowledge [44 percent ] had Inadequate Knowledge.
Assessing overall and domain wise MeanS.D. and mean percentage of underfive children's mothers knowledge on prevention of domestic injuries.

That the maximum score for knowledge was 30 and the total ranges from 4 to 24 with the Mean of 17.58S.D. of 4.93 and mean score percentage of $58.6 \%$.

Domain wise mean knowledge score of under-five children's mothers on prevention of domestic injuries. Domain wise Mean S.D. and mean percentage the maximum mean percentage was on the domain of kind of domestic injuries mean was 5.36 with S.D. of 18 and mean score percentage of $67 \%$ followed by domain on prevention of domestic injuries mean was 5.28 with S.D. of 1.6 and mean score percentage of $52.8 \%$ for domain on management of domestic injuries mean was 3.72 with S.D. of 1.8 and main score percentage of 53.14 and least percentage was on the domain of general information mean was 3.32 with S.D. of 1.3 and mean score percentage of $66.4 \%$.

\section{Section C: - Associate the Knowledge Level with Selected Demographic Variables of Under-Five Children's}




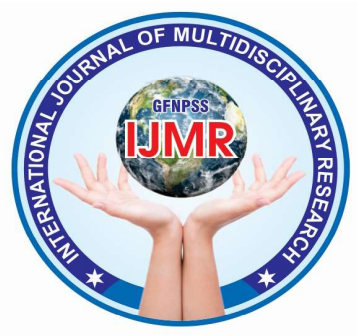

Mothers on Prevention of Domestic Injuries.

Associating the knowledge level with selected demographic variables of underfive children's mothers on prevention of domestic injuries.

Other demographic variables such as age, education, faith, profession, monthly salary, family type, and the number of children under the age of five have no meaningful correlation.

\section{DISCUSSION:}

- The study's results are presented under the following headings and are dependent on the study's objectives.

- The study found that [26 percent] of mothers with children under the age of five had insufficient knowledge, [60 percent] had reasonably adequate knowledge, and [14 percent] had adequate knowledge about the avoidance of domestic accidents.

- In the realm of general information on preventing domestic injury, 30\% had insufficient knowledge, 26\% had moderate knowledge, and $44 \%$ had adequate knowledge.
- In the domain of types of domestic injuries, 28\% had insufficient knowledge, $38 \%$ had moderate knowledge, and 34\% had adequate knowledge.

- In terms of domestic injury avoidance, [48 percent] had insufficient knowledge, [48 percent] had moderate knowledge, and $[4$ percent $]$ had acceptable knowledge. [44 percent] possessed insufficient knowledge, [46 percent] modest knowledge, and [10 percent] sufficient knowledge.

- The study's findings are consistent with those of a study performed on mothers of children under the age of five. The study's key goal was to decide which variables from the main pool of experience predict general health questionnaire casernes in mothers of children under the age of five.

- There was no significant association between levels of knowledge with all the demographic variables hence the [H0] hypothesis stated as there is no significant association in knowledge level of mothers with their selected demographic variables is accepted. 


\section{CONCLUSION:}

The study was based on the following assumption.

This study assumes that the under-five children's mothers possess inadequate knowledge regarding prevention of domestic injuries.

There is no important relationship between mothers' expertise level and their chosen demographic variables, according to the hypothesis.

The research took a descriptive approach. The descriptive research design was chosen for the analysis, with a quantitative approach using a non-probability simple sampling technique to draw samples.

The research variables in the sample were experience of domestic accidents, which were analysed using both descriptive and inferential statistical analysis.

Final findings of the present study $14 \%$ mothers were having adequate knowledge $60 \%$ were having moderate knowledge and
$26 \%$ were having inadequate knowledge regarding prevention of domestic injuries.

There was No Significant Association of knowledge with all demographic variables such as age education religion occupational type of family income number of under-five children source of information.

\section{BIBLIOGRAPHY}

I. Porter AP Perry AG fundamentals of nursing $6^{\text {th }}$ edition ST Louis mosby publisher 200690.

II. Basavanthappa BT community health Nursing $2^{\text {nd }}$ edition Jaypee publisher 200890.

III. Bose George Joseph drawing in childhood Indian pediatric reports 2000 $3782-83$.

IV. The preliminary program for IADR Iranian section annual meeting cause of death in under-five2009 December 3031.

V. Datta Parul pediatric Nursing $2^{\text {nd }}$ edition Jaypee publishers 